\title{
Functional profiling of the endometrium transcriptome during preimplantation development in Finnsheep, Texel and their F1 crosses
}

\author{
Kisun Pokharel ${ }^{1}$, Jaana Peippo ${ }^{1}$, Meng-Hua Li ${ }^{2}$ and Juha Kantanen ${ }^{1}$ \\ ${ }^{1}$ Natural Resources Institute of Finland (Luke), Jokioinen, Finland \\ ${ }^{2}$ College of Animal Science and Technology, China Agricultural University, Beijing, China \\ e-mail: menghua.li@cau.edu.cn, juha.kantanen@luke.fi
}

\begin{abstract}
Carefully coordinated interaction between the endometrium and embryo is critical for the establishment and maintenance of pregnancy in mammals. By exploring the gene expression dynamics of this tissue during preimplantation development, we may be able to get insight into the genetic mechanisms of reproduction during early pregnancy. Here, we have performed comparative transcriptome profiling of the endometrium in response to spherical (Day 7 to Day 12) and elongated (Day 13 to Day 17) embryos in Finnsheep, Texel and their F1 crosses using RNA sequencing (RNA-seq) approach. A total of 21125 genes were expressed in our dataset of which 554 were significantly (absolute log2 fold change $>2.5$; adjusted $p$-value $<0.01$ ) upregulated in the endometrium with elongated embryos. Highly abundant autosomal genes in the endometrium were associated with biological processes such as facilitation of maternal recognition of pregnancy, trophoblast elongation and implantation (LGALS15, CST3, CST6, and EEF1A1). Several endogenous retroviruses (ERVs) including a novel ERV gene located in a reduced FecL locus potentially associated with sheep prolificacy were expressed in our dataset. Comparative transcriptome profiling of the endometrium having spherical and elongated embryos revealed distinct gene expression patterns. Genes that were upregulated in response to elongated embryos indicated the importance of immune system at the maternalembryo interface prior to implantation.
\end{abstract}

Key words: endogenous retrovirus, IFNT, embryo, prostaglandins, immune processes

\section{Introduction}

Prolific breeds of sheep such as native Finnsheep are of high economic importance for global sheep industry. Prolificacy is a complex trait mainly defined by ovulation rate and litter size and it is measured by the number of live births (litters). In sheep, the first two to three weeks of pregnancy is the most critical period in determining the litter size because of high embryo mortality during that period (Quinlivan et al. 1966, Bolet 1986, Rickard et al. 2017). Therefore, the endometrium plays equally important role for the high prolificacy in sheep as the ovulation rate.

Establishment of pregnancy in sheep and other domestic ruminants requires continuous reciprocal interaction between the uterus and the conceptus (Geisert et al. 1992, Spencer et al. 2004, Spencer et al. 2007). The endometrium, the lining of the uterus, is the site of implantation. In addition, the outer lining of the endometrium secretes histotroph, a complex mixture of enzymes, growth factors, hormones, transport proteins and other substances that are key to conceptus survival and implantation, pregnancy recognition and placentation (Spencer and Bazer 2004, Forde et al. 2013). Spencer et al. (2004) describe the preimplantation development of sheep as follows: embryos enter uterus around Day 4 after insemination, hatch from zonae pellucidae between Day 8 and Day 9 and form tubular conceptus by Day 11 followed by elongation. The mononuclear cells from the trophectoderm of elongating conceptus synthesize and secrete interferon tau (IFNT) and prostaglandins which are essential for coordinating endometrial functions during early pregnancy (Bazer et al. 2009, Dorniak et al. 2012). In the endometrium IFNT acts in a paracrine manner to inhibit the expression of oxytocin receptor (OTR) thereby preventing luteolysis (Spencer et al. 1995, Spencer and Bazer 2002). In addition, progesterone from the ovarian corpus luteum $(\mathrm{CL})$ also regulates the function of the endometrium and plays key role in mediating the actions of IFNT to signal pregnancy recognition (Ott et al. 1992, Spencer et al. 2004).

Due to the biological complexity of the underlying physiological processes and to technical difficulties in conducting experiments, embryo implantation is still not well understood (Dorniak et al. 2012, Spencer et al. 2013). Despite a large number of pregnancy-related studies in sheep, (Spencer et al. 2004, Spencer et al. 2007, Mamo et al. 2012, Bazer 2013, Raheem 2017), only a handful of experiments have applied whole transcriptome based RNA sequencing (RNA-seq) approaches to the endometrium. Recently, we compared endometrial gene expression differences between Finnsheep and European mouflon, and identified several genes associated with 


\section{AGRICULTURAL AND FOOD SCIENCE}

K. Pokharel et al. (2020) 29: 331-345

reproductive processes (Yang et al. 2019). Transcriptome analyses of pretransfer embryos and the endometrium identified several genes with potential indicator to pregnancy success in cattle (Salilew-Wondim et al. 2010). Another study reported over expression of several immune-related genes including cytokines in the bovine endometrium as a result of lipopolysaccharide (LPS) treatment (Guo et al. 2019). Brooks et al. (2016) evaluated gene expression profiles of the endometrium during early pregnancy in sheep. Here, we have used RNA sequencing (RNA-seq) approach to compile a list of genes expressed in the endometrium and compared the expression profiles of the endometrium having spherical and elongated forms of embryos during preimplantation development in sheep. We have included native Finnsheep, Texel and their F1 crosses in our study and due to inadequate biological replicates, we were unable to perform breed-wise differential expression analysis. The dataset presented in this paper is part of a larger project which aimed to understand the genetic basis of prolificacy in sheep by conducting experiments on two different time points during establishment of pregnancy: follicular growth phase and early pregnancy prior to implantation.

\section{Materials and methods \\ Experimental design}

Procedures for animal handling and sample collection were approved by the Southern Finland Animal Experiment Committee (approval no. ESAVI/5027/04.10.03/2012). Endometrial samples were collected from the uterine horns with a cytobrush, which was rinsed in a tube containing RNAprotect Cell Reagent (Qiagen, Valencia, CA, USA). The experimental procedures have been described in more detail in an earlier study (Pokharel et al. 2018). RNA-seq libraries of 18 ewes representing Finnsheep $(n=6)$, Texel $(n=6)$ and F1-crosses of purebreds $(n=6)$ were sequenced in the Illumina HiSeq 2000 system following paired-end ( 2 x 100 bp) strategy. Library preparation and sequencing was done in Finnish Microarray and Sequencing Center, Turku, Finland and have been described previously (Pokharel et al. 2020).

\section{Bioinformatic analyses}

The raw sequence reads were assessed for errors and the presence of adapters using FastQC v0.11.6 (https:// github.com/s-andrews/FastQC). As we noticed the presence of adapters, Trim Galore v0.5.0 (https://github.com/ FelixKrueger/TrimGalore) was used to remove the adapters and low-quality reads and bases. The transcripts were quantified under the quasi-mapping-based mode in Salmon v0.11.2 (Patro et al. 2017). We extracted the FASTA sequences (oar31_87.fa) of the sheep transcriptome (oar31_87.gtf) using the gffread utility (Trapnell et al. 2010) and built the transcriptome index. The resulting index was used for transcript quantification (also known as pseudo alignment) of the RNA-seq reads.

The Salmon-based transcript counts were summarized to gene level using tximport v1.12.3 (Soneson et al. 2016). DESeq2 v1.24.0 (Love et al. 2014) was used for gene expression analyses. We compared gene expression profiles of the endometrium from ewes before (Day 7 to Day 12) and after (Day 13 to Day 17) embryonic elongation phase (see also Fig. 2). All replicates were collapsed before running DESeq. Differentially expressed genes with absolute log2 fold change (abs(log2FoldChange) $)>2.5$ and adjusted $p$-value $($ padj $)<0.01$ were considered significant.

All the expressed genes were annotated with Bioconductor biomaRt v2.40.5 (Durinck et al. 2005) to retrieve additional information (gene name, gene description, and chromosome number). Gene ontology (GO) terms and Kyoto Encyclopedia of Genes and Genomes (KEGG) pathways associated with significantly up- and downregulated genes were derived using Cluego v2.5.5 (Bindea et al. 2009) application in Cytoscape v3.7.2 (Shannon et al. 2003). Similar terms and pathways were grouped together using kappa score and only the terms and pathways that include at least 6 genes and 6\% of genes from given GO term or KEGG pathway were taken. The enrichment analysis was performed using right-sided hypergeometric test with Bonferroni stepdown correction method. All the genes expressed in our dataset was used as a reference set for the gene enrichment analysis.

When we noticed that many genes lacked gene annotations, we manually searched for additional information of unannotated genes from the subset of top abundant $(n=25)$ and significantly differentially expressed $(n=40)$ genes. First, we extracted the coding sequence (CDS) of each novel gene using Ensembl BioMart. All genes that had CDS were BLASTed against the nonredundant (NR) nucleotide database. For the BLAST-based annotation, we chose the hit with the highest coverage and the highest percentage of sequence identity to the query sequence. Gene IDs that lacked CDS were queried back to the Ensembl database to retrieve existing information. Throughout the paper, the genes that were annotated based on the BLAST results have been marked with an asterisk (*), while those that were annotated based on information available in Ensembl are marked with a hash/pound (\#). 


\section{AGRICULTURAL AND FOOD SCIENCE}

\section{Results and discussion Phenotype observations}

Several tissue biopsies were collected at the slaughterhouse of which ovarian CL (Pokharel et al. 2020) and the endometrium were employed for RNA-seq. Based on the visual inspection, we observed hatching on Day 7. Similarly, the shape of the embryos was either spherical (Day 7 to Day 12) or elongated (Day 13 to Day 17). Hereinafter, based on the anatomy of embryos, the two group of the endometrium samples are referred to as spherical (S) and elongated (E). Both of our observations are in disagreement with previous report (Spencer et al. 2004) and need further validation. One possibility for the difference could be due to inaccurate estimation of embryonic age in our samples. Nevertheless, the transition time from spherical to elongated embryo appeared to be very short to classify them into intermediary (tubular) shape which have also been explained by the gene expression results (see also Fig. 2).

\section{RNA-seq data}

From the 21 RNA-seq libraries 1065.3 million (M) of paired-end reads were sequenced, and after trimming and quality filtering, approximately $3 \%$ of the reads were discarded. On average, $63 \%$ of the clean reads were mapped to the ovine reference transcriptome (Ensembl release 92). The raw Fastq data were deposited to European Nucleotide Archive (ENA) and are publicly available under project PRJEB32852 (Table 1).

\begin{tabular}{|c|c|c|c|c|c|c|}
\hline $\begin{array}{c}\text { Sample } \\
\text { name }\end{array}$ & Breed & $\begin{array}{l}\text { Age of } \\
\text { embryo }\end{array}$ & $\begin{array}{c}\text { Shape of } \\
\text { embryo }\end{array}$ & ENA Accession & $\begin{array}{c}\text { \# of paired } \\
\text { end-reads (M) }\end{array}$ & $\begin{array}{l}\text { Mapped } \\
\text { reads (M) }\end{array}$ \\
\hline 1033 & $\mathrm{TX}$ & 7 & $S$ & ERR3349024 & 58.6 & 37 \\
\hline $107 A$ & $\mathrm{TX}$ & 10 & $S$ & ERR3349026 & 53.1 & 33 \\
\hline 107B & $\mathrm{TX}$ & 10 & $\mathrm{~S}$ & ERR3349028 & 44.3 & 27.5 \\
\hline 251 & $\mathrm{TX}$ & 9 & $S$ & ERR3349030 & 46.9 & 28.1 \\
\hline 302 & $\mathrm{TX}$ & 17 & $\mathrm{E}$ & ERR3349032 & 53.7 & 33 \\
\hline $312 \mathrm{~A}$ & FS & 11 & $S$ & ERR3349034 & 46.6 & 28.3 \\
\hline $312 B$ & FS & 11 & $S$ & ERR3349036 & 37.1 & 22.6 \\
\hline 3609 & FS & 7 & $S$ & ERR3349038 & 50.8 & 31.5 \\
\hline 379 & $\mathrm{TX}$ & 15 & $E$ & ERR3349040 & 54.2 & 34.5 \\
\hline 4208 & $\mathrm{~F} 1$ & 9 & $S$ & ERR3349042 & 52.1 & 32.3 \\
\hline $4271 \mathrm{~A}$ & $\mathrm{~F} 1$ & 16 & $E$ & ERR3349044 & 45.6 & 30.1 \\
\hline $4271 B$ & $\mathrm{~F} 1$ & 16 & $E$ & ERR3349046 & 44.3 & 29.3 \\
\hline 4519 & $\mathrm{~F} 1$ & 13 & $E$ & ERR3349048 & 54 & 35 \\
\hline 4563 & $\mathrm{~F} 1$ & 9 & $S$ & ERR3349050 & 56.3 & 34.9 \\
\hline 4590 & F1 & 11 & $S$ & ERR3349052 & 41.9 & 25.3 \\
\hline 4823 & $\mathrm{~F} 1$ & 15 & $\mathrm{E}$ & ERR3349054 & 54.3 & 35.5 \\
\hline 48 & FS & 12 & $S$ & ERR3349056 & 53.1 & 33.4 \\
\hline 554 & FS & 15 & $E$ & ERR3349058 & 56.1 & 36.6 \\
\hline 73 & TX & 10 & $S$ & ERR3349060 & 52.6 & 32.5 \\
\hline 897 & FS & 15 & $E$ & ERR3349062 & 51.6 & 33.2 \\
\hline 974 & FS & 15 & $\mathrm{E}$ & ERR3349064 & 58.1 & 37.6 \\
\hline
\end{tabular}

Sample Name = unique name for each sample including technical replicates (represented by A and B e.g. 107A and 107B); Breed = name of the breeds, Finnsheep (FS), Texel (TX) and F1 (F1 crosses of Finnsheep and Texel); age of embryo represents the number of pregnancy days when slaughtered; shape of embryo was visually inspected and were categorized as spherical (S) and elongated (E). ENA Accession = individual accession codes for all samples; \# of paired-end reads = number of paired-end ( 2 × $100 \mathrm{bp})$ reads in millions; and Mapped reads $(\mathrm{M})=$ number (in millions) of clean reads aligned to ovine reference transcriptome. 


\section{AGRICULTURAL AND FOOD SCIENCE}

K. Pokharel et al. (2020) 29: 331-345

\section{Gene expression in the endometrium}

A total of 21125 genes were expressed in the whole data set which represent $\sim 72.5 \%$ of known $(n=29118)$ sheep genes available in Ensembl. The complete list of genes with TPM (transcript count per million of reads) greater than 0.1 is available as a supplementary table (Table S1). The total number of genes expressed in the endometrium was comparatively higher than that in ovaries (Pokharel et al. 2018).

Several immunoglobulins (Igs) were expressed in the endometrium samples. Igs are heterodimeric proteins that belong to the Ig superfamily (IgSF) and are composed of two heavy and two light chains, of which the light chain may further consist of a $\mathrm{k}$ or $\lambda$ chain (Williams and Barclay 1988). Interestingly, the structure and organization of the genes enable Igs to be receptive to a virtually unlimited array of antigens rather than being limited to a fixed set of ligands (Honjo 1983). This feature is particularly important for adaptation to changing environments and may have contributed to enabling Finnsheep, for example, to survive in the harsh Finnish climate. Studies on human have shown that Igs, in general, improve pregnancy success (De Placido et al. 1994, Coulam and Goodman 2000). In addition to 11 Ig genes representing both the light and heavy chains, the joining chain of multimeric IgA and IgM (JCHAIN) was also expressed. JCHAIN is a small polypeptide containing eight cysteine residues that makes disulfide (C-C) bonds with IgA and IgM to form multimers. Two of the eight cysteines are linked with cysteines available on the heavy chain of IgA or IgM to result in dimer or pentamer forms, respectively (Bastian et al. 1995).
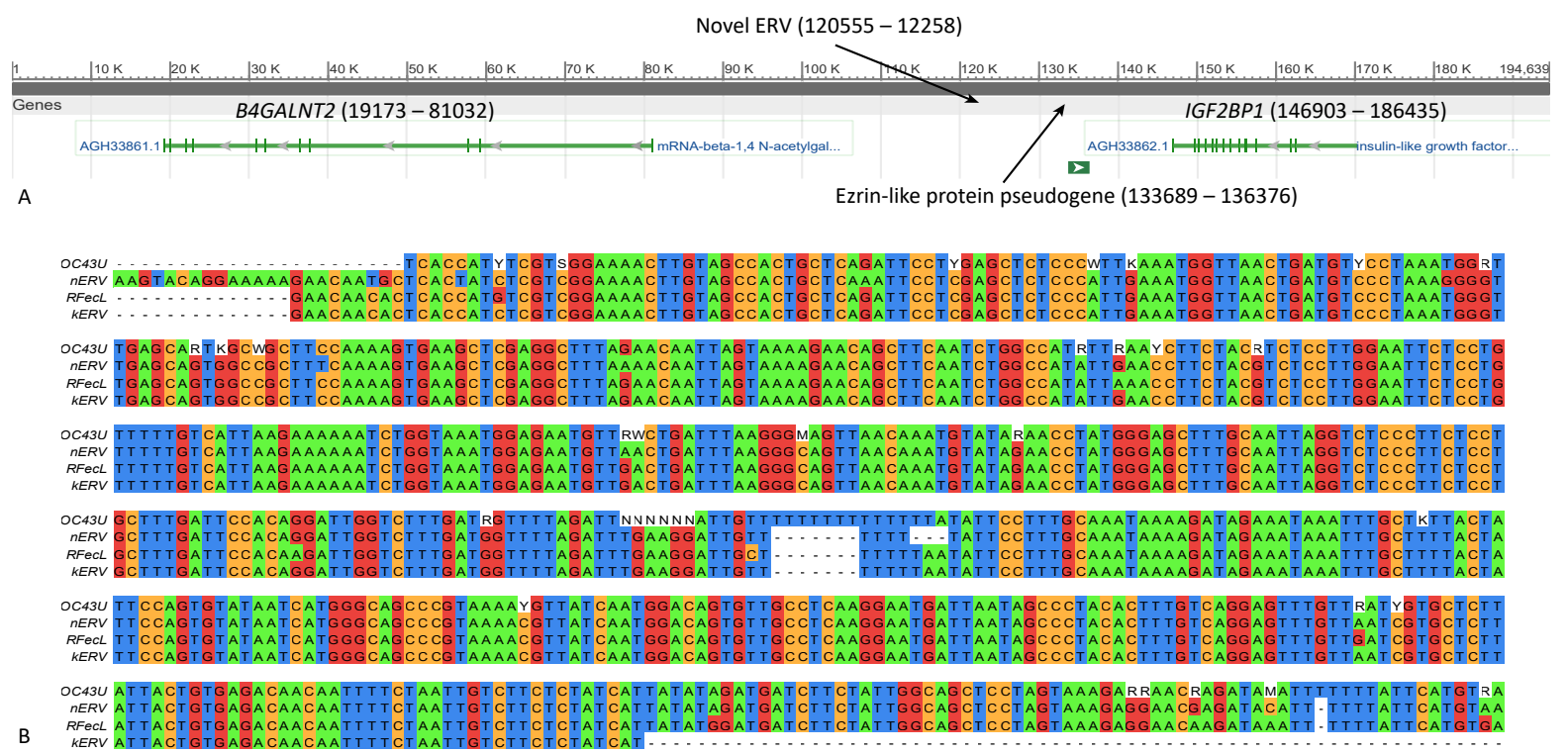

Fig. 1. Multiple sequence alignment (partial) of the novel endogenous retrovirus gene. (A) The novel ERV identified in this study belongs to FecL locus and is located between B4GALNT2 and ezrin-like protein pseudogene. (B) The multiple sequence alignment was prepared using Clustal Omega (Madeira et al. 2019) based on the novel ERV (nERV, ENSOARG00000009959), ovine endogenousvirus beta-2 pro/pol region, partial sequence (KERV, AY193894.1), Ovis canadensis canadensis isolate 43U chromosome 17 sequence (OC43U, CP011902.1) and the reverse complement of reduced FecL locus (RFecL, KC352617). The bases are colored based on the nucleotide coloring scheme in Jalview (Waterhouse et al. 2009).

We also identified several genes associated with endogenous retroviruses (ERVs) in the endometrium samples. ERVs are copies of retroviral genomes that have been integrated into the host genome during evolution. Sheep ERVs share sequence similarity with exogenous and pathogenic Jaagsiekte sheep retrovirus (JSRV) (DeMartini et al. 2003). The genome of sheep contains at least 32 ERVs related to JSRV (Sistiaga-Poveda and Jugo 2014), and these ERVs are essential during pregnancy, including during placental morphogenesis and conceptus elongation (Palmarini et al. 2001, Dunlap et al. 2006a, Spencer and Palmarini 2012). A number of earlier studies have suggested critical roles of ERVs in uterine protection from viral infection, preimplantation conceptus development and placental morphogenesis (Dunlap et al. 2005, Dunlap et al. 2006a, Dunlap et al. 2006b, Denner 2016). Interestingly, one of the novel genes (ENSOARG00000009959) predicted to be an ERV was part of reduced FecL locus which is linked to prolificacy in French Lacaune breed (Drouilhet et al. 2013). Located on the reverse strand of 


\section{AGRICULTURAL AND FOOD SCIENCE}

K. Pokharel et al. (2020) 29: 331-345

chromosome $\mathrm{X}$, this gene has 24 paralogs and is absent in 162 (out of 184) species available in the Ensembl database. Although Ensembl lists 71 orthologs of this gene, none of them have even $50 \%$ sequence homology. A BLAST search against the NR database showed that $97 \%$ of the bases matched to the region of the reduced FecL locus (GenBank ID KC352617.1), which was recently characterized (Drouilhet et al. 2013). So far, only two genes, beta-1,4 N-acetylgalactosaminyltransferase 2 (B4GALNT2) and insulin-like growth factor 2 mRNA-binding protein 1 (IGF2BP1), and a pseudogene, ezrin-like protein, are known to exist in that region; our results have added one additional gene. In addition to the finding that the best hit was related to the FecL locus, the gene appeared to be an ERV, as we noticed that the query gene had $98 \%$ sequence identity with a partial sequence of the endogenous-virus beta-2 pro/pol region (see also Fig. 1). Finally, several lincRNAs were also expressed in the dataset. LincRNAs are long ncRNAs (IncRNAs) that originate from intergenic regions and do not overlap a protein-coding transcript. LincRNAs have a wide array of functions, including transcriptional regulation, biogenesis, epigenetic regulation, tissue specificity and developmental patterning (Pauli et al. 2011, Ulitsky and Bartel 2013, Deniz and Erman 2017, Ransohoff et al. 2018).

\section{Most highly expressed genes}

To obtain an overview of the most abundant genes in the endometrium, we selected the top 25 genes (Table 2). We noticed that nine out of the top 25 genes were mitochondrial genes. Mitochondrial genes play prominent roles during reproduction. We also observed high levels of expression of mitochondrial genes in the ovaries during the follicular growth phase (Pokharel et al. 2018). Top expressed autosomal genes appeared to have substantial roles during the preimplantation stage. Translationally controlled tumor protein (TCTP) is a highly conserved, multifunctional protein that plays essential roles in development and other biological processes in different species (Tuynder et al. 2002, Chen et al. 2007, Brioudes et al. 2010, Li et al. 2011, Branco and Masle 2019). With a maximum level of expression on Day 5 of pregnancy, this protein has been shown to play a significant role in embryo implantation in mice (Li et al. 2011). Consistent with these earlier studies, TCTP appeared to have the highest level of expression during the embryo implantation period. Matrix Gla protein (MGP) is a vitamin K-dependent extracellular matrix protein whose expression is known to be correlated with development and maturation processes (Zhao and Nishimoto 1996, Zhao and Warburton 1997) and receptor-mediated adhesion to the extracellular matrix (Loeser and Wallin 1992). Several studies have reported that MGP is highly expressed in the bovine endometrium (Spencer et al. 1999, Mamo et al. 2012, Forde et al. 2013). The high level of MGP expression in our current and previous (Pokharel et al. 2020) studies is consistent with earlier reports where this gene was found to be elevated during the preimplantation stage in sheep (Spencer et al. 1999, Gray et al. 2006) and cattle (Mamo et al. 2012). Similarly, Casey et al. (2005) reported that MGP was significantly upregulated in nonregressed compared to regressed bovine CLs. Our data and supporting results from earlier studies on cattle show that MGP is highly expressed in both tissues during the preimplantation stage and plays important roles in superficial implantation and placentation in sheep.

Six of the top 25 genes (NUPR1, BCL2L15, CST3, CST6, S100G, and OST4; see Table 2 for descriptions) expressed in the endometrium were also found to be highly abundant in a recent study that compared gene expression changes in the luteal and glandular epithelium during the peri-implantation stage in sheep (Brooks et al. 2016). Galectin 15 (LGALS15) is induced by IFNT and is involved in conceptus development and implantation (Kim et al. 2003, Gray et al. 2004, Lewis et al. 2007). Furthermore, LGALS15 facilitates adhesion of the trophectoderm to the endometrial luminal epithelium (Lewis et al. 2007, Spencer et al. 2007). Two cystatin (CST) family members, namely, cystatin C (CST3) and cystatin E/M (CST6), were highly expressed in the endometrium. Known for their importance during the elongation and implantation of the conceptus, CSTs are protease inhibitors that are initiated by progesterone, and their high expression levels are attributable to stimulation by IFNT (Spencer et al. 2008, Spencer et al. 2015). Elongation factor 1-alpha (EEF1A1) is an important component of the protein synthesis machinery because it transports aminoacyl tRNA to the A sites of ribosomes in a GTP-dependent manner (Tatsuka et al. 1992, Mateyak and Kinzy 2010). The high level of EEF1A1 in the endometrium most likely correspond to the production and transport of progesterone and other molecules that are essential during the implantation stage. The exact function of BCL2-like 15 (BCL2L15) in the sheep endometrium is not known, nor has it been reported in the endometria of other species, but its high expression has been reported previously (Koch et al. 2010, Brooks et al. 2016, Romero et al. 2017). 
Table 2. List of the 25 most abundant genes in the endometrium. The table includes the Ensembl gene ID (GenelD), abundance measured by number of transcripts per million reads (TPM), chromosome number (Chr; MT refers to mitochondrial genome and AMGL01125506.1 is an unplaced scaffold), and gene description. Gene IDs and annotations that were not available in BioMart were retrieved based on a homology search using the nucleotide BLAST (marked with an asterisk, "*”) or on information available in Ensembl (marked with a hash, "\#”).

\begin{tabular}{|c|c|c|c|c|}
\hline Gene ID & Abundance (TPM) & Gene name & $\mathrm{Chr}$ & Gene description \\
\hline ENSOARG00000007815 & 34771.26 & LOC105580399* & 6 & $\begin{array}{l}\text { Cercocebus atys } 60 \mathrm{~S} \text { ribosoma } \\
\text { protein L41-like }\end{array}$ \\
\hline ENSOARG00000019088 & 33284.80 & LGALS15 & AMGL01125506.1 & galectin 15 \\
\hline ENSOARG00000000037 & 25447.87 & Mt tRNA\# & MT & mitochondrial tRNA \\
\hline ENSOARG00000020724 & 21124.83 & MGP & 3 & matrix Gla protein \\
\hline ENSOARG00000003793 & 15373.87 & TSMB4X & 23 & thymosin beta- 4 \\
\hline ENSOARG00000000016 & 14147.12 & $\operatorname{cox} 1$ & MT & Cytochrome c oxidase subunit 1 \\
\hline ENSOARG00000000023 & 10341.99 & COIII & MT & Cytochrome $\mathrm{c}$ oxidase subunit 3 \\
\hline ENSOARG00000000022 & 9327.50 & ATP6 & MT & ATP synthase subunit a \\
\hline ENSOARG00000007617 & 9130.00 & TCTP & 10 & $\begin{array}{l}\text { tumor protein, translationally } \\
\text { controlled, } 1\end{array}$ \\
\hline ENSOARG00000000021 & 8535.39 & ATP8 & MT & ATP synthase protein 8 \\
\hline ENSOARG00000003184 & 8523.87 & NUPR1 & 24 & $\begin{array}{l}\text { nuclear protein } 1 \text {, transcriptiona } \\
\text { regulator }\end{array}$ \\
\hline ENSOARG00000019924 & 8089.16 & $B C L 2 L 15$ & 1 & BCL2 like 15 \\
\hline ENSOARG00000006202 & 6230.27 & CST3 & 13 & cystatin C \\
\hline ENSOARG00000000035 & 5973.32 & CYTB & MT & cytochrome b (mitochondrion) \\
\hline ENSOARG00000001346 & 5551.71 & CST6 & 21 & cystatin $\mathrm{E} / \mathrm{M}$ \\
\hline ENSOARG00000016080 & 5472.76 & ATP5F1E & 13 & ATP synthase F1 subunit epsilon \\
\hline ENSOARG00000021079 & 5469.74 & S100A11 & 1 & S100 calcium binding protein $\mathrm{A} 11$ \\
\hline ENSOARG00000003341 & 5184.15 & IFI6 & 2 & interferon alpha inducible protein 6 \\
\hline ENSOARG00000000006 & 5179.55 & ND1 & MT & $\begin{array}{l}\text { NADH-ubiquinone oxidoreductase } \\
\text { chain } 1\end{array}$ \\
\hline ENSOARG00000018666 & 5119.04 & $R P L P 1$ & 7 & $\begin{array}{l}\text { ribosomal protein lateral stalk } \\
\text { subunit P1 }\end{array}$ \\
\hline ENSOARG00000000028 & 5104.93 & ND4 & MT & $\begin{array}{l}\text { NADH-ubiquinone oxidoreductase } \\
\text { chain } 4\end{array}$ \\
\hline ENSOARG00000019491 & 4871.67 & OST4 & 3 & $\begin{array}{l}\text { oligosaccharyltransferase complex } \\
\text { subunit } 4 \text {, non-catalytic }\end{array}$ \\
\hline ENSOARG00000003782 & 4816.16 & $B 2 M$ & 7 & Beta-2-microglobulin \\
\hline ENSOARG00000013018 & 4768.67 & S100G & $x$ & S100 calcium binding protein $\mathrm{G}$ \\
\hline ENSOARG00000000019 & 4710.35 & $\operatorname{cox} 2$ & MT & Cytochrome c oxidase subunit 2 \\
\hline
\end{tabular}

Differentially expressed genes in the endometrium having spherical and elongated embryos

Principal component analysis (PCA) based on variance stabilized transformation (VST) of expressed genes clearly indicated two distinct groups (Fig. 2A). Similarly, a heatmap plot of sample distances also based on VST showed a similar pattern (Fig. 2B). The two main clusters are primarily reflecting gene expression dynamics of the endometrium before (Day 7 to Day 12) and after (Day 13 to Day 17) embryonic elongation phase (see also Table 1). The anatomical difference in two groups was verified by manual inspection of the embryos whereby all embryos collected from Day 7 to Day 12 were spherical $(S)$ and the rest were elongated (E).

Altogether 1410 genes were significantly (padj < 0.01 and abs $(\log 2$ FoldChange $>2.5)$ ) differentially expressed between $S$ and $E$ of which 554 were upregulated in $E$ and the rest $(n=856)$ were upregulated in $S$. Several of the non-classical IFNT-stimulated genes (ISGs) including LGALS15, HSD11B1, SLC7A2, ISG20, CLEC4F, CCL8, CXCL11, CXCL10, and CST6 were upregulated in E (Spencer et al. 2008, Brooks et al. 2014). All these ISGs are known to 


\section{AGRICULTURAL AND FOOD SCIENCE}

K. Pokharel et al. (2020) 29: 331-345

be induced by the progesterone and are critical for conceptus elongation (Brooks et al. 2014). We observed high abundance of key genes involved in progesterone production in the CL of the studied animals (Pokharel et al. 2020) which complements findings from this data. This is consistent with maximal production of IFNT which causes massive changes in the endometrial gene expression starting Day 13 of pregnancy (Gray et al. 2006, Spencer et al. 2007, Forde and Lonergan 2017). Nine chemokines (CCL2, CCL3, CCL4, CCL8, CCRL2, CXCL9, CXCL10, CXCL11, CXCR1) were all upregulated in $\mathrm{E}$. Chemokines serve a variety of functions including migration of immune cells to the site of inflammation, chemotaxis, angiogenesis, cell differentiation, and signal transduction (Luther and Cyster 2001, Thelen 2001, Fernandez and Lolis 2002, Griffith et al. 2014). Numerous reports have suggested the role of chemokines and their receptors in establishing proper environment for implantation by facilitating orientation and adhesion of conceptus to the uterine wall (van Mourik et al. 2009, Sakumoto et al. 2017, Imakawa et al. 2017, Złotkowska and Andronowska 2019). In our another study, chemokines (including CXCL9) were also expressed in the $\mathrm{CL}$ and were upregulated in prolific Finnsheep compared to Texel (Pokharel et al. 2020). Upregulated expression of several chemokines and their receptors indicated their prominent role during early pregnancy. Similarly, several members from the complement system including 10 complements, three galectins (LGALS3, LGALS7, LGALS15), two selectins (SELE, SELP), mannan binding lectin serine peptidase 1 (MASP1), and C-type lectin domain family 4 member $F(C L E C 4 F)$ were upregulated in $E$. Half of the complement genes $(n=5)$ significantly upregulated in $E$ are in the unplaced scaffold of the sheep reference genome (Oarv3.1) and C1QL2 was the tenth most upregulated ( $L F C=7.4, \mathrm{Padj}=3.28 \mathrm{E}-27$ ) gene in $\mathrm{E}$. It has been well established that complement system has important role in successful establishment of pregnancy. C1Q in particular is known to have significant role at the implantation site whereby it promotes trophoblast invasion in maternal decidua (Singh et al. 2011, Bulla et al. 2012). While some of the genes (e.g. LGALS15, CLEC4F) involved in the complement system have been extensively studied, more research will be needed to elucidate the role of complement genes during the implantation window of pregnancy.
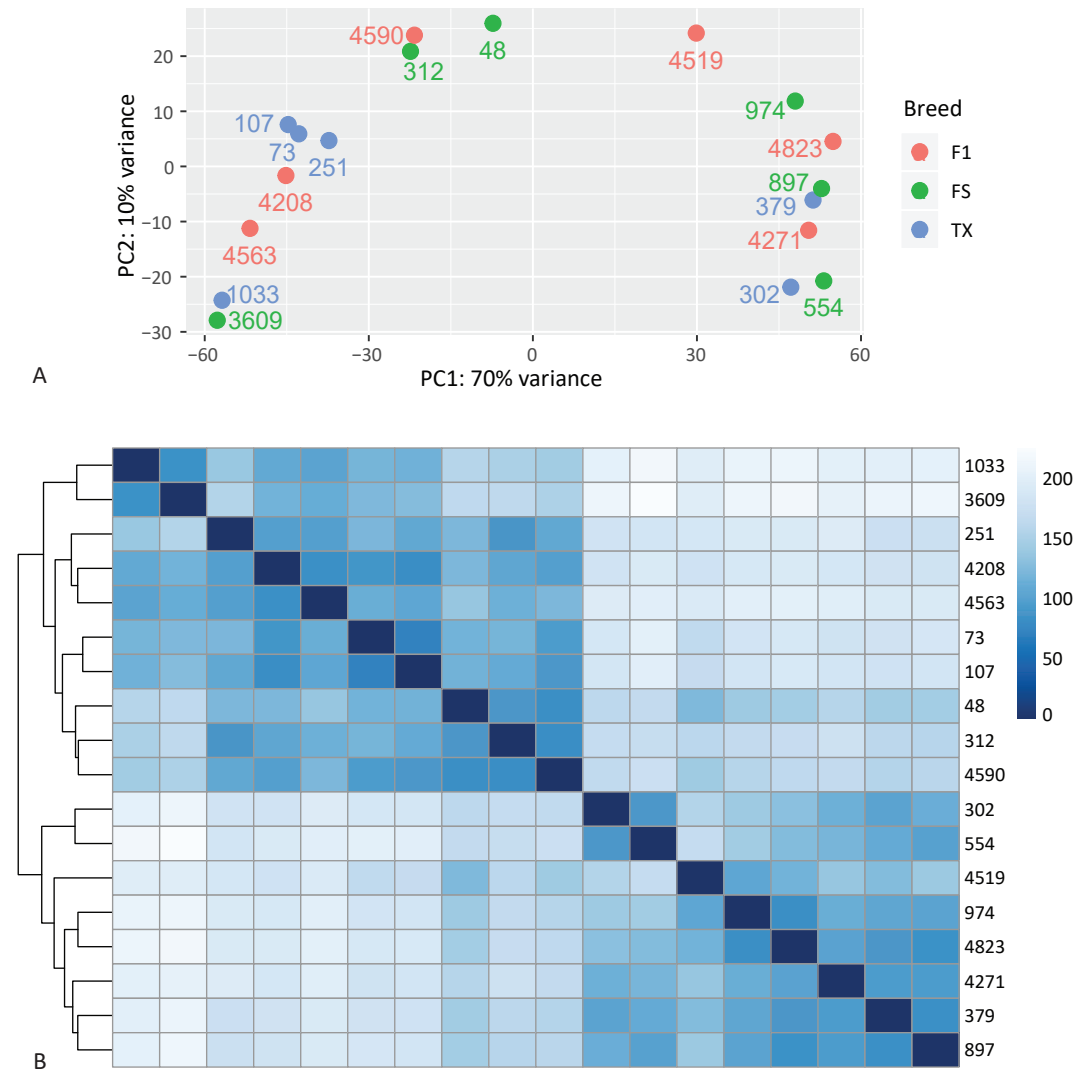

Fig. 2. Sample relatedness. (A) PCA plot of samples representing Finnsheep (FS), Texel (TX) and F1 crosses (F1) based on normalized counts. (B) Heatmap plot of sample distance matrix

Prostaglandin F synthase 1-like (PGFS1) was the most significantly upregulated (LFC $=11.4$, Padj $=4.51 \mathrm{E}-77$ ) gene in E group (Table 3). Prostaglandins, mainly secreted by the endometrium are another important regulators of embryo development (Dorniak et al. 2011, Spencer et al. 2013). Two dehydrogenase enzymes (DHDH and HSD3B1) were among the top 20 upregulated genes in E. Two additional dehydrogenases (HSD11B1 and HSD11B2) were also differentially expressed in our data of which HSD11B1 was upregulated and HSD11B2 was downregulated in E. 


\section{AGRICULTURAL AND FOOD SCIENCE}

K. Pokharel et al. (2020) 29: 331-345

Table 3. Top 40 significantly differentially expressed genes between the endometrium having spherical (S; Day 7 to Day 12) and elongated (E; Day 13 to Day 16) embryos in sheep. The genes were ranked based on the log2 fold change (LFC) values. First 20 genes (with positive LFC values) were the top upregulated genes in E and the rest (bottom 20 with negative LFC) were upregulated in S. Few genes lacking annotations were derived from homology based BLAST search against the non-redundant (NR) database (marked with *) or from the Ensembl (marked with \#). For the complete list of significantly differentially expressed genes, see Table S2.

\begin{tabular}{|c|c|c|c|c|c|}
\hline Gene ID & Mean count & LFC & padj & Gene name & Gene description \\
\hline ENSOARG00000012196 & 1117.02 & 11.46 & $9.12 \mathrm{E}-77$ & PGFS1 & prostaglandin F synthase 1-like \\
\hline ENSOARG00000011663 & 271.36 & 10.53 & $9.55 \mathrm{E}-48$ & $\mathrm{DHDH}$ & dihydrodiol dehydrogenase 3-like \\
\hline ENSOARG00000007954 & 791.69 & 8.61 & $2.84 \mathrm{E}-44$ & FGFBP1 & fibroblast growth factor-binding protein 1 \\
\hline ENSOARG00000015726 & 405.88 & 8.30 & $2.26 \mathrm{E}-39$ & DCSTAMP & $\begin{array}{l}\text { dendrocyte expressed seven transmembrane } \\
\text { protein }\end{array}$ \\
\hline ENSOARG00000016674 & 1927.54 & 8.26 & $2.89 \mathrm{E}-17$ & PLET1 & placenta-expressed transcript 1 protein \\
\hline ENSOARG00000020537 & 9334.75 & 8.22 & $2.38 \mathrm{E}-31$ & CRYGS & crystallin gamma $\mathrm{S}$ \\
\hline ENSOARG00000016590 & 58.03 & 7.74 & $8.39 E-21$ & TRIM29 & tripartite motif containing 29 \\
\hline ENSOARG00000020896 & 48.99 & 7.51 & $3.30 \mathrm{E}-15$ & MUC17* & mucin 17-like \\
\hline ENSOARG00000008599 & 6530.38 & 7.51 & $6.47 \mathrm{E}-22$ & SLC36A2 & solute carrier family 36 member 2 \\
\hline ENSOARG00000012340 & 216.26 & 7.39 & $3.28 \mathrm{E}-25$ & C1QL2 & complement C1q like 2 \\
\hline ENSOARG00000020029 & 182.35 & 7.22 & $3.19 \mathrm{E}-47$ & FBXO40 & F-box protein 40 \\
\hline ENSOARG00000004524 & 36.23 & 7.21 & 2.17E-14 & SPINKO* & serine peptidase inhibitor, kazal type 9 \\
\hline ENSOARG00000020026 & 16.37 & 7.00 & $2.43 \mathrm{E}-22$ & ARGFX & arginine-fifty homeobox \\
\hline ENSOARG00000025059 & 44.93 & 6.92 & $2.17 \mathrm{E}-24$ & SCARNA6* & small Cajal body-specific RNA 6 \\
\hline ENSOARG00000011075 & 59.03 & 6.80 & $1.72 \mathrm{E}-17$ & SELE & selectin $\mathrm{E}$ \\
\hline ENSOARG00000020398 & 17.03 & 6.76 & $3.63 \mathrm{E}-16$ & HAO2 & hydroxyacid oxidase 2 \\
\hline ENSOARG00000006417 & 17.41 & 6.73 & $1.81 \mathrm{E}-15$ & TTBK1 & tau tubulin kinase 1 \\
\hline ENSOARG00000004790 & 328.60 & 6.72 & $6.40 \mathrm{E}-10$ & MMP13 & matrix metallopeptidase 13 \\
\hline ENSOARG00000020402 & 13084.60 & 6.69 & $6.35 \mathrm{E}-29$ & HSD3B1 & $\begin{array}{l}\text { hydroxy-delta-5-steroid dehydrogenase, } 3 \text { beta- } \\
\text { and steroid delta-isomerase } 1\end{array}$ \\
\hline ENSOARG00000005877 & 57.14 & 6.62 & $5.44 \mathrm{E}-13$ & $T K D P 1^{*}$ & Trophoblast Kunitz domain protein 1 \\
\hline ENSOARG00000018477 & 72.96 & -6.63 & $1.68 \mathrm{E}-16$ & PRSS16 & serine protease 16 \\
\hline ENSOARG00000016704 & 159.31 & -6.66 & $1.23 \mathrm{E}-16$ & CNGA1 & cyclic nucleotide gated channel alpha 1 \\
\hline ENSOARG00000009436 & 52.81 & -6.86 & $2.74 \mathrm{E}-15$ & SLITRK4 & SLIT and NTRK like family member 4 \\
\hline ENSOARG00000001686 & 38.40 & -6.91 & $4.41 \mathrm{E}-15$ & HAVCR1* & hepatitis A virus cellular receptor 1 \\
\hline ENSOARG00000010567 & 69.04 & -7.05 & $1.18 \mathrm{E}-19$ & STATH* & statherin \\
\hline ENSOARG00000003097 & 433.14 & -7.10 & $6.36 \mathrm{E}-40$ & C8orf34 & $\begin{array}{l}\text { chromosome } 9 \text { open reading frame, human } \\
\text { C8orf34 }\end{array}$ \\
\hline ENSOARG00000004187 & 657.19 & -7.15 & $9.22 \mathrm{E}-13$ & SMIM18 & small integral membrane protein 18 \\
\hline ENSOARG00000002992 & 1741.32 & -7.26 & $3.14 \mathrm{E}-28$ & HAVCR1* & hepatitis A virus cellular receptor 1 \\
\hline ENSOARG00000004092 & 71.45 & -7.30 & $4.96 \mathrm{E}-18$ & CLDN22* & claudin 22 \\
\hline ENSOARG00000026762 & 808.19 & -7.38 & $1.21 \mathrm{E}-30$ & LincRNA\# & \\
\hline ENSOARG00000006412 & 126.01 & -7.53 & $1.53 \mathrm{E}-15$ & MGAT5B & $\begin{array}{l}\text { alpha-1,6-mannosylglycoprotein } 6 \text {-beta- } \mathrm{N} \text { - } \\
\text { acetylglucosaminyltransferase B }\end{array}$ \\
\hline ENSOARG00000025314 & 67.94 & -7.54 & $1.80 \mathrm{E}-17$ & LincRNA\# & \\
\hline ENSOARG00000013676 & 1091.06 & -7.54 & $1.51 \mathrm{E}-19$ & SUSD2* & sushi domain containin 2 \\
\hline ENSOARG00000018755 & 6302.26 & -7.73 & $1.49 \mathrm{E}-29$ & TNNI1 & troponin I1, slow skeletal type \\
\hline ENSOARG00000019210 & 311.45 & -7.91 & $2.80 \mathrm{E}-19$ & CPS1 & carbamoyl-phosphate synthase 1 \\
\hline ENSOARG00000011999 & 236.10 & -8.01 & $8.12 \mathrm{E}-31$ & JPH3 & junctophilin 3 \\
\hline ENSOARG00000010828 & 19130.13 & -8.03 & $5.25 \mathrm{E}-41$ & HAVCR1* & hepatitis A virus cellular receptor 1 \\
\hline ENSOARG00000010754 & 4415.85 & -8.08 & $1.34 \mathrm{E}-43$ & HAVCR1* & hepatitis A virus cellular receptor 1 \\
\hline ENSOARG00000000132 & 1328.32 & -8.09 & $1.90 \mathrm{E}-24$ & SUSD2* & sushi domain containing 2 \\
\hline ENSOARG00000009890 & 258.25 & -8.13 & $1.28 \mathrm{E}-29$ & RTL4* & retrotransposon Gag-like protein 4 \\
\hline
\end{tabular}




\section{AGRICULTURAL AND FOOD SCIENCE}

K. Pokharel et al. (2020) 29: 331-345

This finding was in part consistent with earlier study that reported the abundance of HSD11B1 in the endometrium between Days 12 and 16 while HSD11B2 was abundant in the conceptus (Simmons et al. 2010). FGFBP1, a secreted protein functions as a chaperone of FGFs to their receptors (Tassi et al. 2001, Tassi et al. 2011). FGF14, FGF11, FGF10, FGF13, FGF9 and FGF21 were significantly differentially expressed between E and S of which FGF14 and FGF11 were upregulated in $S$ and the rest were upregulated in E. DCSTAMP is a recently characterized protein known to regulate osteoclastogenesis by mediating cell-cell fusion in osteoclasts (Hartgers et al. 2000, Yagi et al. 2005, Chiu and Ritchlin 2016). Although the function of this gene in the endometrium remains to be elucidated, we speculate that it has important role in attachment of conceptus to the uterine wall. TKDP4, belongs to a member of rapidly evolving secreted proteins predominantly expressed in the trophoblast of placenta during adhesion of conceptus to the endometrium (Chakrabarty et al. 2006, Clemente et al. 2011).

More than $50 \%$ of the top 20 upregulated genes in S lacked gene descriptions indicating that the existing knowledge on endometrial expressed genes with respect to spherical embryos is rather limited. Some of the highly upregulated genes in S such as CPS1 (Gu et al. 2014), TNNI1 (Rehman et al. 2003), PRSS16 (Forde et al. 2013) were expressed in the endometrium of pregnant animals but their precise function was not reported. Notably, four (ENSOARG00000010754, ENSOARG00000010828, ENSOARG00000002992 and ENSOARG00000001686) of the top 20 genes upregulated in $S$ had high sequence similarity to hepatitis A virus cellular receptor 1 (HAVCR1*). Moreover, two lincRNAs (ENSOARG00000025314, ENSOARG00000026762) were also highly significantly upregulated in S. A recent study on the placental transcriptome of mare reported the expression of SPINK9 (Loux et al. 2019). Further research and improved genome annotation will be required to get a better picture of the gene expression changes in the endometrium in response to non-elongated embryos.

\section{Biological processes and pathways of differentially expressed genes}

Altogether $52 \mathrm{GO}$ terms related to the biological processes category were associated with the genes upregulated in E group (Table S3). Further merging of the terms using kappa score (see methods section) led to 14 groups. "Receptor regulator activity (GO:0030505)" was one of the most significantly enriched GO terms associated with upregulated genes in E. Majority of the 52 significant GO terms associated with upregulated genes in E were related to immune processes, followed by transport related processes (Table 4, Table S3). Other categories include "embryonic placenta development", "perception of sound" and "monocarboxylic acid metabolic process".

Table 4. Selected GO terms associated with genes that were upregulated in endometrium having elongated (E) embryos (for more details and complete list, see Table S5)

\begin{tabular}{|c|c|c|}
\hline GO ID & GO Term & Associated genes \\
\hline GO:0001892 & $\begin{array}{l}\text { embryonic placenta } \\
\text { development }\end{array}$ & EPAS1, GCM1, IL10, LEF1, LIF, SOCS3 \\
\hline GO:0002684 & $\begin{array}{l}\text { positive regulation of } \\
\text { immune system process }\end{array}$ & $\begin{array}{l}\text { ACOD1, C5, CARD11, CDKN1A, CXCL10, DCSTAMP, DPP4, FCN1, FGF10, FGR, } \\
\text { GATA1, GPLD1, IL6, ITGB3, LEF1, LGALS3, LGMN, LIF, LOC443475, LYN, MASP1, PGC, } \\
\text { PGLYRP4, S100A14, SELP, SEMA7A, SERPING1, TLR2, TLR5, TNFSF18, TNIP3, TTBK1 }\end{array}$ \\
\hline GO:0052548 & $\begin{array}{l}\text { regulation of } \\
\text { endopeptidase activity }\end{array}$ & $\begin{array}{l}\text { AHSG, C5, CAST, COL28A1, CRYAB, CST3, CST6, CSTB, FABP1, LEF1, LGMN, } \\
\text { LOC101123265, LOC101123672, LXN, LYN, SERPINB5, SERPING1, TNFSF10, TTBK1 }\end{array}$ \\
\hline GO:0032787 & $\begin{array}{l}\text { monocarboxylic acid } \\
\text { metabolic process }\end{array}$ & $\begin{array}{l}\text { ACOT7, ACOX2, ACSM1, ACSM3, ADH1C, ADIPOQ, ALDH8A1, ANGPTL3, CYP1A1, } \\
\text { FABP3, GATM, HAL, HAO2, PCK1, PLA2G1B, SDS, SLC27A2 }\end{array}$ \\
\hline GO:0046651 & lymphocyte proliferation & CARD11, CDKN1A, CTPS1, FGF10, GPNMB, IL10, IL6, LEF1, LGALS3, LYN, TNFSF18 \\
\hline GO:0009617 & response to bacterium & $\begin{array}{l}\text { ACOD1, ADIPOQ, CUBN, CXCL10, CXCL9, FAM20A, FGR, IL10, IL6, LOC443322, } \\
\text { LY6G6C, LYN, NUGGC, PCK1, PGC, PGLYRP4, PLA2G1B, S100A14, SLC10A2, TLR2, } \\
\text { TLR5, TNFSF4, TNIP3 }\end{array}$ \\
\hline GO:0022804 & $\begin{array}{l}\text { active transmembrane } \\
\text { transporter activity }\end{array}$ & $\begin{array}{l}\text { ATP12A, ATP2B2, ATP2B3, LOC101106534, LOC101109370, LOC101113819, } \\
\text { SLC10A2, SLC13A1, SLC15A1, SLC22A4, SLC23A1, SLC28A2, SLC36A2, SLC4A5, } \\
\text { SLC6A13, SLCO1C1 }\end{array}$ \\
\hline GO:0006935 & chemotaxis & $\begin{array}{l}\text { C5, CCRL2, CXCL10, CXCL11, CXCL9, CXCR1, DOCK4, FGF10, GBX2, ISL2, LEF1, } \\
\text { LGALS3, LGMN, LOC101114285, LOC101114535, LOC101119572, LOC101119832, } \\
\text { LYN, MATN2, S100A14, SEMA6A }\end{array}$ \\
\hline GO:0030545 & receptor regulator activity & $\begin{array}{l}\text { ADIPOQ, ANGPTL3, CXCL10, CXCL11, CXCL9, FGF10, FGF13, FGF21, FGF9, FST, } \\
\text { GPNMB, IL10, IL6, LGALS3, LIF, LOC101110855, LOC101114285, LOC101114535, } \\
\text { LOC101119572, LOC101119832, LY6G6D, RETN, TNFSF10, TNFSF4 }\end{array}$ \\
\hline
\end{tabular}


GO terms associated with transporter activities and metabolic processes were also enriched in E. Majority $(n=6)$ of the 19 KEGG pathways associated with the genes upregulated in E were signaling pathways such as "chemokine signaling pathway", "JAK-STAT signaling pathway", "PPAR signaling pathway". In addition pathways related to diseases ("malaria", "pertussis", "Staphylococcus aureus infection", "rheumatoid arthritis"), secretions ("bile-secretion", "salivary secretion", "pancreatic secretion") and metabolism ("pyrimidine metabolism", "retinol metabolism") were also in the list (Table S4). The importance of robust, adaptive and responsive immune system during early pregnancy has been well documented. However, several of the GO terms and KEGG pathways associated with early pregnancy should be redefined. In particular, categories related with diseases and bacterial infections may not be relevant in the context of implantation and placentation as all animals included in the study were healthy. In recently published report on human placenta, authors did not find any evidence of bacterial infection (de Goffau et al. 2019). Moreover, it should also be noted that many of the immune related genes have characteristics that are well suited for the processes leading to implantation such as apposition, adhesion and interaction between the conceptus and the endometrium.

Biological processes and pathways enriched by upregulated genes in S group were substantially different than those from upregulated genes in E. Functional analysis of 856 genes upregulated in S revealed $143 \mathrm{GO}$ terms that were further categorized into 25 groups (Table S5). Transport related GO terms were the most common and included ion (e.g. potassium, sodium, chloride, organic, and inorganic) transports, amino acid transport, carboxylic acid transport, channel activities and transmembrane transporter activities (Table 5, Table S5). Several GO terms associated with development (limb, connective tissue, neural crest cell, mesenchyme, ear, eye, sensory system, heart, neural tube, muscle tissue, etc.) and morphogenesis (cardiac chamber, sensory organ, epithelial tube, embryonic limb, tissue, etc.) were associated with the upregulated genes in S. These tissue and organ development related GO terms are not relevant and may rather point to general development related processes in the endometrium. For example, as shown in Table S5, many of the genes present in ear or eye development categories are also present in tissue morphogenesis. In the context of this study, tissue morphogenesis makes better sense than organ development. Similarly, several signaling pathways, and those related to "cholesterol metabolism", "ECM-receptor interaction", "axon guidance", "GABAergic synapse", "cell adhesion molecules (CAMS)" etc. were enriched by genes upregulated in S (Table S6). Wnt signaling pathway is known to have important role in conceptus elongation (Mohamed et al. 2005).

Table 5. Selected GO terms associated with the genes that were upregulated in the endometrium having spherical (S) conceptus (for more details and complete list, see Table S5)

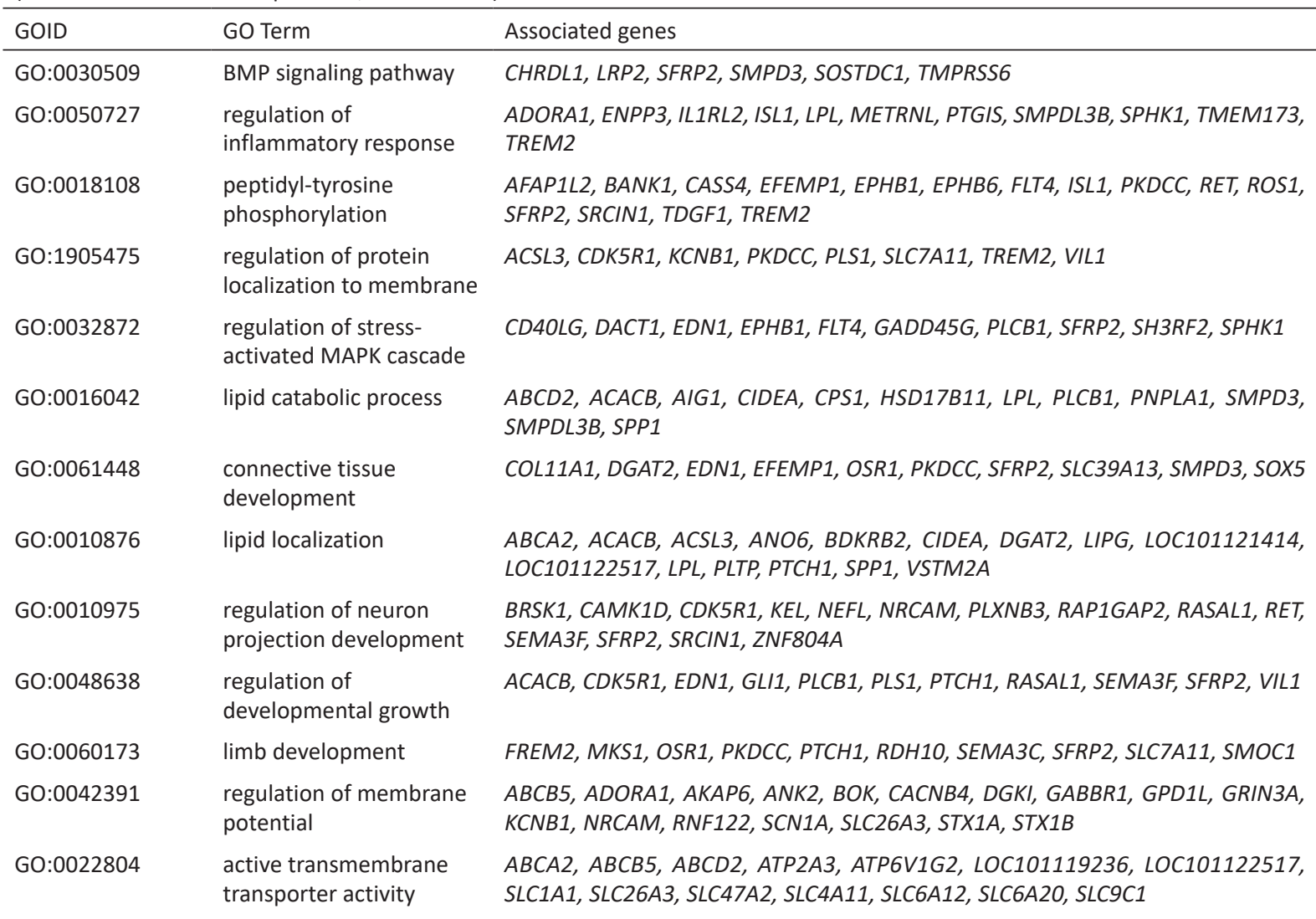




$\begin{array}{ll}\text { GO:0050808 } & \text { synapse organization } \\ \text { GO:0044057 } & \begin{array}{l}\text { regulation of system } \\ \text { process }\end{array} \\ \text { GO:0007389 } & \begin{array}{l}\text { pattern specification } \\ \text { process }\end{array} \\ \text { GO:0007267 } & \text { cell-cell signaling }\end{array}$

GO:0014070

GO:0048729

GO:0099537

GO:0007507

GO:0006811 compound

heart development

ion transport
CACNB4, CDK5R1, CDKL5, COL4A5, EPHB1, INA, L1CAM, NEFL, NRCAM, SEMA3F, SLC7A11, SLITRK4, SRCIN1, SYNDIG1, WASF1

ADORA1, ANK2, EDN1, GPD1L, HOMER3, LOC101120030, NMU, NOS1, SLC1A1, SPHK1, SPX, STX1A, STX1B, THRB, TMEM98, TNNC1, TNNT1, TPM1

CDON, DNAH5, EDN1, GLI1, GRHL3, HOXB1, ISL1, LRP2, MKS1, OSR1, PTCH1, SEMA3C, SEMA3F, SFRP2, SOSTDC1, SUFU

ADORA1, ANK2, ANXA9, BRSK1, CACNB4, DACT1, DGKI, EDN1, EPHB1, GABBR1, GLI1, GRHL3, GRID2IP, GRIN3A, HMGN3, HOMER3, ILDR1, ISL1, JADE1, JPH3, JPH4, KCNB1, LGR5, LOC101119591, LOC443240, MC4R, MKS1, MME, NOS1, PLAT, PLCB1, PLEKHG5, PLK2, PYGO1, RAB26, RNF43, SFRP2, SHC3, SLC7A11, SMPD3, SNCAIP, SOSTDC1, SPP1, STX1A, STX1B, SV2C, SYN2

response to organic cyclic $A B A T, A B C A 2, A K A P 6, B G L A P, C I D E A, E S R 2, K C N J 8, L O C 101122517, L Y 6 D, N R O B 1$, NR2E3, NR2F1, PADI2, PPP1R1B, PTCH1, RORB, RORC, RXRG, SLC26A3, SLC7A11, SPP1, SRARP, THRB, TMEM173, VDR

tissue morphogenesis

BRSK1, COL11A1, EDN1, FAT4, FREM2, GRHL3, ISL1, KRT27, LGR5, LRP2, MKS1, MTHFD1L, OSR1, PTCH1, RDH10, RET, SEMA3C, SFRP2, SOSTDC1, SUFU, SYNE4, TNNC1, TPM1, VDR

trans-synaptic signaling

ADORA1, ANXA9, BRSK1, CACNB4, DGKI, EDN1, EPHB1, GABBR1, GRID2IP, GRIN3A, HOMER3, JPH3, JPH4, KCNB1, LOC101119591, MME, NOS1, PLAT, PLCB1, PLEKHG5, PLK2, RAB26, SHC3, SLC7A11, SNCAIP, STX1A, STX1B, SV2C, SYN2

ACACB, ADAMTS6, ANK2, COL11A1, DNAH5, EDN1, FAT4, FREM2, GATA4, GLI1, ISL1, KCNJ8, LRP2, MKS1, MYO18B, OSR1, PDLIM3, PTCH1, SEMA3C, SFRP2, SUFU, TDGF1, TNNC1, TPM1
ACSL3, AKAP6, ANK2, ANO6, ATP2A3, ATP6V1G2, BDKRB2, CACNB4, CDH23, CLDN10, CLIC5, CNGA1, CP, GABRR2, GPD1L, GRIN3A, JPH3, JPH4, KCNB1, KCNG4, KCNJ8, KCNK12, KCNK2, KCNN1, KEL, LOC101108019, LOC101111082, LOC101116002, LOC101116975, LOC101119236, LOC101122517, LOC101122774, LRP2, MCOLN2, MCOLN3, NOS1, OSR1, PLTP, RHCG, ROS1, RYR3, SCN1A, SCN2A, SCN3A, SCNN1A, SLC1A1, SLC25A42, SLC26A3, SLC38A3, SLC39A13, SLC4A11, SLC6A12, SLC6A20, SLC7A11, SLC7A7, SLC9C1, SLCO5A1, STX1A, TRPV6, VDR

\section{Conclusion}

Collectively, the data uncovered the pattern of endometrial gene expression in relation to spherical and elongated embryos during preimplantation window of early pregnancy. To that end, the endometrium having spherical embryos displayed a distinct transcriptome profile compared to endometrium compared to those with elongated embryos. The roles of retroviruses during early pregnancy were indicated in our data. A novel gene sharing similarity with an ERV was identified in the FecL locus. The importance of adaptive immune system at the embryomaternal interface was clearly indicated in our data. Due to lack of enough replicates, we were unable to perform breed-wise gene expression comparison. Moreover, it would be very interesting to see how gene expression during pregnancy development changes with respect to the number of viable embryos (Finnsheep have higher number of embryos than Texel).

\section{Acknowledgments}

This study was funded by the Academy of Finland (decisions 250633, 250677 and 285017). This study is part of the ClimGen ("Climate Genomics for Farm Animal Adaptation") project funded by FACCE-JPI ERA-NET Plus on Climate Smart Agriculture. K.P. acknowledges financial support from the Niemi Foundation.

We are grateful to Anu Tuomola for providing the experimental facilities on her farm in Urjala and to Kati Kaisajoki from Lallin Lammas Ltd. for providing the slaughtering facilities. We thank Mervi Honkatukia, Johanna Rautiainen, Arja Seppälä, Annukka Numminen, Kalle Saastamoinen, Ilma Tapio, Tuula Marjatta Hamama, Anneli Virta and Magnus Andersson for their valuable assistance during this study. Special thanks to two anonymous reviewers for their constructive comments which improved the quality of this manuscript. The authors wish to acknowledge the CSC - IT Center for Science, Finland, for computational resources. This study was supported by the Finnish Functional Genomics Centre of the University of Turku, Åbo Akademi and Biocenter Finland. 


\section{References}

Bastian, A., Kratzin, H., Fallgren-Gebauer, E., Eckart, K. \& Hilschmann, N. 1995. Intra- and inter chain disulfide bridges of J chain in Human S-IgA. Advances in Experimental Medicine and Biology 371A: 581-583. https://doi.org/10.1007/978-1-4615-1941-6_122

Bazer, F.W. 2013. Pregnancy recognition signaling mechanisms in ruminants and pigs. Journal of Animal Science and Biotechnology 4: 23. https://doi.org/10.1186/2049-1891-4-23

Bazer, F.W., Spencer, T.E. \& Johnson, G.A. 2009. Interferons and uterine receptivity. Seminars in Reproductive Medicine 27: 90102. https://doi.org/10.1055/s-0028-1108013

Bindea, G., Mlecnik, B., Hackl, H., Charoentong, P., Tosolini, M., Kirilovsky, A., Fridman, W.-H., Pagès, F., Trajanoski, Z. \& Galon, J. 2009. ClueGO: a Cytoscape plug-in to decipher functionally grouped gene ontology and pathway annotation networks. Bioinformatics 25: 1091-1093. https://doi.org/10.1093/bioinformatics/btp101

Bolet, G. 1986. Timing and extent of embryonic mortality in pigs, sheep and goats: Genetic Variability. In: Sreenan, J.M. \& Diskin, M.G. (eds.). Embryonic mortality in farm animals. Current topics in Veterinary Medicine and Animal Science (CTVM, volume 34). Dordrecht, Netherlands: Springer. p. 12-43. https://doi.org/10.1007/978-94-009-5038-2_2

Branco, R. \& Masle, J. 2019. Systemic signalling through TCTP1 controls lateral root formation in Arabidopsis. Journal of Experimental Botany 70: 3927-3940. https://doi.org/10.1093/jxb/erz204

Brioudes, F., Thierry, A.-M., Chambrier, P., Mollereau, B. \& Bendahmane, M. 2010. Translationally controlled tumor protein is a conserved mitotic growth integrator in animals and plants. Proceedings of the National Academy of Sciences of the United States of America 107: 16384-16389. https://doi.org/10.1073/pnas.1007926107

Brooks, K., Burns, G. \& Spencer, T.E. 2014. Conceptus elongation in ruminants: roles of progesterone, prostaglandin, interferon tau and cortisol. Journal of Animal Science and Biotechnology 5: 53. https://doi.org/10.1186/2049-1891-5-53

Brooks, K., Burns, G.W., Moraes, J.G.N. \& Spencer, T.E. 2016. Analysis of the uterine epithelial and conceptus transcriptome and luminal fluid proteome during the peri-Implantation period of pregnancy in sheep. Biology of Reproduction 95: 88-88. https://doi.org/10.1095/biolreprod.116.141945

Bulla, R., Bossi, F. \& Tedesco, F. 2012. The complement system at the embryo implantation site: friend or foe? Frontiers in Immunology 3: 55. https://doi.org/10.3389/fimmu.2012.00055

Casey, O.M., Morris, D.G., Powell, R., Sreenan, J.M. \& Fitzpatrick, R. 2005. Analysis of gene expression in non-regressed and regressed bovine corpus luteum tissue using a customized ovarian cDNA array. Theriogenology 64: 1963-1976. https://doi.org/10.1016/j.theriogenology.2005.04.015

Chakrabarty, A., MacLean, J.A., Hughes, A.L., Roberts, R.M. \& Green, J.A. 2006. Rapid evolution of the trophoblast kunitz domain proteins (TKDPs)-a multigene family in ruminant ungulates. Journal of Molecular Evolution 63: $274-282$. https://doi.org/10.1007/s00239-005-0264-3

Chen, S.H., Wu, P.-S., Chou, C.-H., Yan, Y.-T., Liu, H., Weng, S.-Y. \& Yang-Yen, H.-F. 2007. A knockout mouse approach reveals that TCTP functions as an essential factor for cell proliferation and survival in a tissue- or cell type-specific manner. Molecular Biology of the Cell 18: 2525-2532. https://doi.org/10.1091/mbc.e07-02-0188

Chiu, Y.-H. \& Ritchlin, C.T. 2016. DC-STAMP: A key regulator in osteoclast differentiation. Journal of Cellular Physiology 231: 24022407. https://doi.org/10.1002/jcp.25389

Clemente, M., Lopez-Vidriero, I., O’Gaora, P., Mehta, J.P., Forde, N., Gutierrez-Adan, A., Lonergan, P. \& Rizos, D. 2011. Transcriptome changes at the initiation of elongation in the bovine conceptus. Biology of Reproduction 85: 285-295. https://doi.org/10.1095/biolreprod.111.091587

Coulam, C.B. \& Goodman, C. 2000. Increased pregnancy rates after IVF/ET with intravenous immunoglobulin treatment in women with elevated circulating C56+ cells. Early Pregnancy 4: 90-98.

de Goffau, M.C., Lager, S., Sovio, U., Gaccioli, F., Cook, E., Peacock, S.J., Parkhill, J., Charnock-Jones, D.S. \& Smith, G.C.S. 2019. Human placenta has no microbiome but can contain potential pathogens. Nature 572: 329-334. https://doi.org/10.1038/s41586-019-1451-5

De Placido, G., Zullo, F., Mollo, A., Cappiello, F., Nazzaro, A., Colacurci, N. \& Palumbo, G. 1994. Intravenous immunoglobulin (IVIG) in the prevention of implantation failures. Annals of the New York Academy of Sciences 734: $232-234$. https://doi.org/10.1111/j.1749-6632.1994.tb21751.x

DeMartini, J.C., Carlson, J.O., Leroux, C., Spencer, T. \& Palmarini, M. 2003. Endogenous retroviruses related to jaagsiekte sheep retrovirus. Current Topics in Microbiology and Immunology 275: 117-137. https://doi.org/10.1007/978-3-642-55638-8_5

Deniz, E. \& Erman, B. 2017. Long noncoding RNA (lincRNA), a new paradigm in gene expression control. Functional \& Integrative Genomics 17: 135-143. https://doi.org/10.1007/s10142-016-0524-x

Denner, J. 2016. Expression and function of endogenous retroviruses in the placenta. APMIS 124: 31-43. https://doi.org/10.1111/apm.12474

Dorniak, P., Bazer, F.W. \& Spencer, T.E. 2011. Prostaglandins regulate conceptus elongation and mediate effects of interferon tau on the ovine uterine endometrium. Biology of Reproduction 84: 1119-1127. https://doi.org/10.1095/biolreprod.110.089979

Dorniak, P., Bazer, F.W., Wu, G. \& Spencer, T.E. 2012. Conceptus-derived prostaglandins regulate endometrial function in sheep. Biology of Reproduction 87: 9-7. https://doi.org/10.1095/biolreprod.112.100487

Drouilhet, L., Mansanet, C., Sarry, J., Tabet, K., Bardou, P., Woloszyn, F., Lluch, J., Harichaux, G., Viguié, C., Monniaux, D., Bodin, L., Mulsant, P. \& Fabre, S. 2013. The highly prolific phenotype of lacaune sheep is associated with an ectopic expression of the B4GALNT2 gene within the ovary. PLoS Genetics 9: p.e1003809. https://doi.org/10.1371/journal.pgen.1003809 
Dunlap, K.A., Palmarini, M., Adelson, D.L. \& Spencer, T.E. 2005. Sheep endogenous betaretroviruses (enJSRVs) and the hyaluronidase 2 (HYAL2) receptor in the ovine uterus and conceptus. Biology of Reproduction 73: 271-279. https://doi.org/10.1095/biolreprod.105.039776

Dunlap, K.A., Palmarini, M. \& Spencer, T.E. 2006a. Ovine endogenous betaretroviruses (enJSRVs) and placental morphogenesis. Placenta 27: 135-140. https://doi.org/10.1016/j.placenta.2005.12.009

Dunlap, K.A., Palmarini, M., Varela, M., Burghardt, R.C., Hayashi, K., Farmer, J.L. \& Spencer, T.E. 2006b. Endogenous retroviruses regulate periimplantation placental growth and differentiation. Proceedings of the National Academy of Sciences of the United States of America 103: 14390-14395. https://doi.org/10.1073/pnas.0603836103

Durinck, S., Moreau, Y., Kasprzyk, A., Davis, S., De Moor, B., Brazma, A. \& Huber, W. 2005. BioMart and Bioconductor: a powerful link between biological databases and microarray data analysis. Bioinformatics 21: 3439-3440. https://doi.org/10.1093/bioinformatics/bti525

Fernandez, E.J. \& Lolis, E. 2002. Structure, function, and inhibition of chemokines. Annual Review of Pharmacology and Toxicology 42: 469-499. https://doi.org/10.1146/annurev.pharmtox.42.091901.115838

Forde, N. \& Lonergan, P. 2017. Interferon-tau and fertility in ruminants. Reproduction 154: F33-F43.

Forde, N., Mehta, J.P., McGettigan, P.A., Mamo, S., Bazer, F.W., Spencer, T.E. \& Lonergan, P. 2013. Alterations in expression of endometrial genes coding for proteins secreted into the uterine lumen during conceptus elongation in cattle. BMC Genomics 14: 321. https://doi.org/10.1186/1471-2164-14-321

Geisert, R.D., Morgan, G.L., Short, E.C. \& Zavy, M.T. 1992. Endocrine events associated with endometrial function and conceptus development in cattle. Reproduction, Fertility, and Development 4: 301-305. https://doi.org/10.1071/RD9920301

Gray, C.A., Abbey, C.A., Beremand, P.D., Choi, Y., Farmer, J.L., Adelson, D.L., Thomas, T.L., Bazer, F.W. \& Spencer, T.E. 2006. Identification of endometrial genes regulated by early pregnancy, progesterone, and interferon tau in the ovine uterus. Biology of Reproduction 74: 383-394. https://doi.org/10.1095/biolreprod.105.046656

Gray, C.A., Adelson, D.L., Bazer, F.W., Burghardt, R.C., Meeusen, E.N.T. \& Spencer, T.E. 2004. Discovery and characterization of an epithelial-specific galectin in the endometrium that forms crystals in the trophectoderm. Proceedings of the National Academy of Sciences of the United States of America 101: 7982-7987. https://doi.org/10.1073/pnas.0402669101

Griffith, J.W., Sokol, C.L. \& Luster, A.D. 2014. Chemokines and chemokine receptors: positioning cells for host defense and immunity. Annual Review of Immunology 32: 659-702. https://doi.org/10.1146/annurev-immunol-032713-120145

Gu, T., Zhu, M., Schroyen, M., Qu, L., Nettleton, D., Kuhar, D., Lunney, J.K., Ross, J.W., Zhao, S. \& Tuggle, C.K. 2014. Endometrial gene expression profiling in pregnant Meishan and Yorkshire pigs on day 12 of gestation. BMC genomics 15: 156. https://doi.org/10.1186/1471-2164-15-156

Guo, Y., van Schaik, T., Jhamat, N., Niazi, A., Chanrot, M., Charpigny, G., Valarcher, J.F., Bongcam-Rudloff, E., Andersson, G. \& Humblot, P. 2019. Differential gene expression in bovine endometrial epithelial cells after challenge with LPS; specific implications for genes involved in embryo maternal interactions. PLOS ONE 14: p.e0222081. https://doi.org/10.1371/journal.pone.0222081

Hartgers, F.C., Vissers, J.L., Looman, M.W., van Zoelen, C., Huffine, C., Figdor, C.G. \& Adema, G.J. 2000. DC-STAMP, a novel multimembrane-spanning molecule preferentially expressed by dendritic cells. European Journal of Immunology 30: 3585-3590. https://doi.org/10.1002/1521-4141(200012)30:12<3585::AID-IMMU3585>3.0.CO;2-Y

Honjo, T. 1983. Immunoglobulin genes. Annual Review of Immunology 1: 499van528. https://doi.org/10.1146/annurev.iy.01.040183.002435

Imakawa, K., Bai, R., Fujiwara, H., Ideta, A., Aoyagi, Y. \& Kusama, K. 2017. Continuous model of conceptus implantation to the maternal endometrium. Journal of Endocrinology 233: R53vanR65. https://doi.org/10.1530/JOE-16-0490

Kim, S., Choi, Y., Bazer, F.W. \& Spencer, T.E. 2003. Identification of genes in the ovine endometrium regulated by interferon $\tau$ independent of signal transducer and activator of transcription. Endocrinology 144: 5203van5214. https://doi.org/10.1210/en.2003-0665

Koch, J.M., Ramadoss, J. \& Magness, R.R. 2010. Proteomic profile of uterine luminal fluid from early pregnant ewes. Journal of Proteome Research 9: 3878-3885. https://doi.org/10.1021/pr100096b

Lewis, S.K., Farmer, J.L., Burghardt, R.C., Newton, G.R., Johnson, G.A., Adelson, D.L., Bazer, F.W. \& Spencer, T.E. 2007. Galectin 15 (LGALS15): A gene uniquely expressed in the uteri of sheep and goats that functions in trophoblast attachment. Biology of Reproduction 77: 1027-1036. https://doi.org/10.1095/biolreprod.107.063594

Li, S., Chen, X., Ding, Y., Liu, X., Wang, Y. \& He, J. 2011. Expression of translationally controlled tumor protein (TCTP) in the uterus of mice of early pregnancy and its possible significance during embryo implantation. Human Reproduction 26: 2972-2980. https://doi.org/10.1093/humrep/der275

Loeser, R.F. \& Wallin, R. 1992. Cell adhesion to matrix Gla protein and its inhibition by an Arg-Gly-Asp-containing peptide. The Journal of Biological Chemistry 267: 9459-9462.

Loux, S.C., Dini, P., Ali, H.E.-S., Kalbfleisch, T. \& Ball, B.A. 2019. Characterization of the placental transcriptome through mid to late gestation in the mare. PLOS ONE 14: p.e0224497. https://doi.org/10.1371/journal.pone.0224497

Love, MI., Huber, W. \& Anders, S. 2014. Moderated estimation of fold change and dispersion for RNA-seq data with DESeq2. Genome Biology 15: 550. https://doi.org/10.1186/s13059-014-0550-8

Luther, S.A. \& Cyster, J.G. 2001. Chemokines as regulators of T cell differentiation. Nature Immunology 2: 102-107. https://doi.org/10.1038/84205

Madeira, F., Park, Y, M., Lee, J., Buso, N., Gur, T., Madhusoodanan, N., Basutkar, P., Tivey, A., Potter, S.C., Finn, R.D. \& Lopez, R. 2019. The EMBL-EBI search and sequence analysis tools APIs in 2019. Nucleic Acids Research 47: W636-W641.

https://doi.org/10.1093/nar/gkz268 
Mamo, S., Mehta, J.P., Forde, N., McGettigan, P. \& Lonergan, P. 2012. Conceptus-endometrium crosstalk during maternal recognition of pregnancy in cattle. Biology of Reproduction 87: 6-9. https://doi.org/10.1095/biolreprod.112.099945

Mateyak, M.K. \& Kinzy, T.G. 2010. eEF1A: thinking outside the ribosome. The Journal of Biological Chemistry 285: $21209-21213$. https://doi.org/10.1074/jbc.R110.113795

Mohamed, O.A., Jonnaert, M., Labelle-Dumais, C., Kuroda, K., Clarke, H.J. \& Dufort, D. 2005. Uterine Wnt/beta-catenin signaling is required for implantation. Proceedings of the National Academy of Sciences of the United States of America 102: 8579-8584. https://doi.org/10.1073/pnas.0500612102

van Mourik, M.S.M., Macklon, N.S. \& Heijnen, C.J. 2009. Embryonic implantation: cytokines, adhesion molecules, and immune cells in establishing an implantation environment. Journal of Leukocyte Biology 85: 4-19. https://doi.org/10.1189/jlb.0708395

Ott, T.L., Mirando, M.A., Davis, M.A. \& Bazer, F.W. 1992. Effects of ovine conceptus secretory proteins and progesterone on oxytocin-stimulated endometrial production of prostaglandin and turnover of inositol phosphate in ovariectomized ewes. Journal of Reproduction and Fertility 95: 19-29. https://doi.org/10.1530/jrf.0.0950019

Palmarini, M., Gray, C.A., Carpenter, K., Fan, H., Bazer, F.W. \& Spencer, T.E. 2001. Expression of endogenous betaretroviruses in the ovine uterus: effects of neonatal age, estrous cycle, pregnancy, and progesterone. Journal of Virology 75: 11319-11327. https://doi.org/10.1128/JVI.75.23.11319-11327.2001

Patro, R., Duggal, G., Love, M.I., Irizarry, R.A. \& Kingsford, C. 2017. Salmon provides fast and bias-aware quantification of transcript expression. Nature methods 14: 417-419. https://doi.org/10.1038/nmeth.4197

Pauli, A., Rinn, J.L. \& Schier, A.F. 2011. Non-coding RNAs as regulators of embryogenesis. Nature Reviews Genetics $12: 136-149$. https://doi.org/10.1038/nrg2904

Pokharel, K., Peippo, J., Honkatukia, M., Seppälä, A., Rautiainen, J., Ghanem, N., Hamama, T.-M., Crowe, M.A., Andersson, M., Li, M.-H. \& Kantanen, J. 2018. Integrated ovarian mRNA and miRNA transcriptome profiling characterizes the genetic basis of prolificacy traits in sheep (Ovis aries). BMC Genomics 19: 104. https://doi.org/10.1186/s12864-017-4400-4

Pokharel, K., Peippo, J., Weldenegodguad, M., Honkatukia, M., Li, M.-H. \& Kantanen, J. 2020. Gene expression profiling of corpus luteum reveals important insights about early pregnancy in domestic sheep. Genes 11: 415. https://doi.org/10.3390/genes11040415

Quinlivan, T.D., Martin, C.A., Taylor, W.B. \& Cairney, I.M. 1966. Estimates of pre- and perinatal mortality in the New Zealand Romney Marsh ewe. I. Pre- and perinatal mortality in those ewes that conceived to one service. Journal of Reproduction and Fertility 11: 379-390. https://doi.org/10.1530/jrf.0.0110379

Raheem, K.A. 2017. An insight into maternal recognition of pregnancy in mammalian species. Journal of the Saudi Society of Agricultural Sciences 16: 1-6. https://doi.org/10.1016/j.jssas.2015.01.002

Ransohoff, J.D., Wei, Y. \& Khavari, P.A. 2018. The functions and unique features of long intergenic non-coding RNA. Nature Reviews Molecular Cell Biology 19: 143-157. https://doi.org/10.1038/nrm.2017.104

Rehman, K.S., Yin, S., Mayhew, B.A., Word, R.A. \& Rainey, W.E. 2003. Human myometrial adaptation to pregnancy: cDNA microarray gene expression profiling of myometrium from non-pregnant and pregnant women. Molecular Human Reproduction 9: 681-700. https://doi.org/10.1093/molehr/gag078

Rickard, J.P., Ryan, G., Hall, E., Graaf, S.P. de and Hermes, R. 2017. Using transrectal ultrasound to examine the effect of exogenous progesterone on early embryonic loss in sheep. PLOS ONE 12: p.e0183659. https://doi.org/10.1371/journal.pone.0183659

Romero, J.J., Liebig, B.E., Broeckling, C.D., Prenni, J.E. \& Hansen, T.R. 2017. Pregnancy-induced changes in metabolome and proteome in ovine uterine flushings. Biology of Reproduction 97: 273-287. https://doi.org/10.1093/biolre/iox078

Sakumoto, R., Hayashi, K.-G., Fujii, S., Kanahara, H., Hosoe, M., Furusawa, T. \& Kizaki, K. 2017. Possible roles of CC- and CXCChemokines in regulating bovine endometrial function during early pregnancy. International Journal of Molecular Sciences 18 : 742. https://doi.org/10.3390/ijms18040742

Salilew-Wondim, D., Hölker, M., Rings, F., Ghanem, N., Ulas-Cinar, M., Peippo, J., Tholen, E., Looft, C., Schellander, K. \& Tesfaye, D. 2010. Bovine pretransfer endometrium and embryo transcriptome fingerprints as predictors of pregnancy success after embryo transfer. Physiological Genomics 42: 201-218. https://doi.org/10.1152/physiolgenomics.00047.2010

Shannon, P., Markiel, A., Ozier, O., Baliga, N.S., Wang, J.T., Ramage, D., Amin, N., Schwikowski, B. \& Ideker, T. 2003. Cytoscape: a software environment for integrated models of biomolecular interaction networks. Genome Research 13: $2498-2504$. https://doi.org/10.1101/gr.1239303

Simmons, R.M., Satterfield, M.C., Welsh, T.H., Bazer, F.W. \& Spencer, T.E. 2010. HSD11B1, HSD11B2, PTGS2, and NR3C1 expression in the peri-implantation ovine uterus: effects of pregnancy, progesterone, and interferon tau. Biology of Reproduction 82: 35-43. https://doi.org/10.1095/biolreprod.109.079608

Singh, J., Ahmed, A. \& Girardi, G. 2011. Role of complement component C1q in the onset of preeclampsia in mice. Hypertension 58: 716-724. https://doi.org/10.1161/HYPERTENSIONAHA.111.175919

Sistiaga-Poveda, M. \& Jugo, B.M. 2014. Evolutionary dynamics of endogenous Jaagsiekte sheep retroviruses proliferation in the domestic sheep, mouflon and Pyrenean chamois. Heredity 112: 571-578. https://doi.org/10.1038/hdy.2013.136

Soneson, C., Love, M.I. \& Robinson, M.D. 2016. Differential analyses for RNA-seq: transcript-level estimates improve gene-level inferences. F1000Research 4: 1521. https://doi.org/10.12688/f1000research.7563.2

Spencer, T.E. \& Bazer, F.W. 2002. Biology of progesterone action during pregnancy recognition and maintenance of pregnancy. Frontiers in Bioscience 7: d1879-d1898. https://doi.org/10.2741/A886

Spencer, T.E. \& Bazer, F.W. 2004. Conceptus signals for establishment and maintenance of pregnancy. Reproductive Biology and Endocrinology 2: 49. https://doi.org/10.1016/S0378-4320(04)00070-3 
Spencer, T.E., Becker, W.C., George, P., Mirando, M.A., Ogle, T.F. \& Bazer, F.W. 1995. Ovine interferon-tau inhibits estrogen receptor up-regulation and estrogen-induced luteolysis in cyclic ewes. Endocrinology 136: 4932-4944. https://doi.org/10.1210/endo.136.11.7588227

Spencer, T.E., Forde, N., Dorniak, P., Hansen, T.R., Romero, J.J. \& Lonergan, P. 2013. Conceptus-derived prostaglandins regulate gene expression in the endometrium prior to pregnancy recognition in ruminants. Reproduction 146: 377-387. https://doi.org/10.1530/REP-13-0165

Spencer, T.E., Forde, N. \& Lonergan, P. 2015. The role of progesterone and conceptus-derived factors in uterine biology during early pregnancy in ruminants. Journal of Dairy Science 99: 5941-5950. https://doi.org/10.3168/jds.2015-10070

Spencer, T.E, Johnson, G.A., Bazer, F.W. \& Burghardt, R.C. 2004. Implantation mechanisms: insights from the sheep. Reproduction 128: 657-668. https://doi.org/10.1530/rep.1.00398

Spencer, T.E., Johnson, G.A., Bazer, F.W., Burghardt, R.C. \& Palmarini, M. 2007. Pregnancy recognition and conceptus implantation in domestic ruminants: roles of progesterone, interferons and endogenous retroviruses. Reproduction, Fertility, and Development 19: 65-78. https://doi.org/10.1071/RD06102

Spencer, T.E., Johnson, G.A., Burghardt, R.C. \& Bazer, F.W. 2004. Progesterone and placental hormone actions on the uterus: insights from domestic animals. Biology of Reproduction 71: 2-10. https://doi.org/10.1095/biolreprod.103.024133

Spencer, T.E. \& Palmarini, M. 2012. Endogenous retroviruses of sheep: a model system for understanding physiological adaptation to an evolving ruminant genome. The Journal of reproduction and development 58:33-37. https://doi.org/10.1262/jrd.2011-026

Spencer, T.E., Sandra, O. \& Wolf, E. 2008. Genes involved in conceptus-endometrial interactions in ruminants: insights from reductionism and thoughts on holistic approaches. Reproduction 135: 165-179. https://doi.org/10.1530/REP-07-0327

Spencer, T.E., Stagg, A.G., Joyce, M.M., Jenster, G., Wood, C.G., Bazer, F.W., Wiley, A.A. \& Bartol, F.F. 1999. Discovery and characterization of endometrial epithelial messenger ribonucleic acids using the ovine uterine gland knockout model. Endocrinology 140: 4070-4080. https://doi.org/10.1210/endo.140.9.6981

Tassi, E., Al-Attar, A., Aigner, A., Swift, M.R., McDonnell, K., Karavanov, A. \& Wellstein, A. 2001. Enhancement of fibroblast growth factor (FGF) activity by an fgf-binding protein. Journal of Biological Chemistry 276: 40247-40253. https://doi.org/10.1074/jbc.M104933200

Tassi, E., McDonnell, K., Gibby, K.A., Tilan, J.U., Kim, S.E., Kodack, D.P., Schmidt, M.O., Sharif, G.M., Wilcox, C.S., Welch, W.J., Gallicano, G.I., Johnson, M.D., Riegel, A.T. \& Wellstein, A. 2011. Impact of fibroblast growth factor-binding protein-1 expression on angiogenesis and wound healing. The American Journal of Pathology 179: 2220-2232. https://doi.org/10.1016/j.ajpath.2011.07.043

Tatsuka, M., Mitsui, H., Wada, M., Nagata, A., Nojima, H. \& Okayama, H. 1992. Elongation factor-1 $\alpha$ gene determines susceptibility to transformation. Nature 359: 333-336. https://doi.org/10.1038/359333a0

Thelen, M. 2001. Dancing to the tune of chemokines. Nature Immunology 2: 129-134. https://doi.org/10.1038/84224

Trapnell, C., Williams, B.A., Pertea, G., Mortazavi, A., Kwan, G., van Baren, M.J., Salzberg, S.L., Wold, B.J. \& Pachter, L. 2010. Transcript assembly and quantification by RNA-Seq reveals unannotated transcripts and isoform switching during cell differentiation. Nature Biotechnology 28: 511-515. https://doi.org/10.1038/nbt.1621

Tuynder, M., Susini, L., Prieur, S., Besse, S., Fiucci, G., Amson, R. \& Telerman, A. 2002. Biological models and genes of tumor reversion: cellular reprogramming through tpt1/TCTP and SIAH-1. Proceedings of the National Academy of Sciences of the United States of America 99: 14976-14981. https://doi.org/10.1073/pnas.222470799

Ulitsky, I. \& Bartel, D.P. 2013. lincRNAs: genomics, evolution, and mechanisms. Cell 154: 26-46. https://doi.org/10.1016/j.cell.2013.06.020

Waterhouse, A.M., Procter, J.B., Martin, D.M.A., Clamp, M. \& Barton, G.J. 2009. Jalview Version 2-a multiple sequence alignment editor and analysis workbench. Bioinformatics 25: 1189-1191. https://doi.org/10.1093/bioinformatics/btp033

Williams, A.F. \& Barclay, A.N. 1988. The immunoglobulin superfamily-domains for cell surface recognition. Annual Review of Immunology 6: 381-405. https://doi.org/10.1146/annurev.iy.06.040188.002121

Yagi, M., Miyamoto, T., Sawatani, Y., Iwamoto, K., Hosogane, N., Fujita, N., Morita, K., Ninomiya, K., Suzuki, T., Miyamoto, K., Oike, Y., Takeya, M., Toyama, Y. \& Suda, T. 2005. DC-STAMP is essential for cell-cell fusion in osteoclasts and foreign body giant cells. Journal of Experimental Medicine 202: 345-351. https://doi.org/10.1084/jem.20050645

Yang, J., Li, X., Cao, Y.-H., Pokharel, K., Hu, X.-J., Chen, Z.-H., Xu, S.-S., Peippo, J., Honkatukia, M., Kantanen, J. \& Li, M.-H. 2019. Comparative mRNA and miRNA expression in European mouflon (Ovis musimon) and sheep (Ovis aries) provides novel insights into the genetic mechanisms for female reproductive success. Heredity 122: 172-186. https://doi.org/10.1038/s41437-018-0090-1

Zhao, J. \& Nishimoto, S.K. 1996. Matrix Gla protein gene expression is elevated during postnatal development. Matrix Biology 15: 131-140. https://doi.org/10.1016/S0945-053X(96)90154-7

Zhao, J. \& Warburton, D. 1997. Matrix Gla protein gene expression is induced by transforming growth factor-beta in embryonic lung culture. American Journal of Physiology-Lung Cellular and Molecular Physiology 273: L282-L287. https://doi.org/10.1152/ajplung.1997.273.1.L282

Złotkowska, A. \& Andronowska, A. 2019. Chemokines as the modulators of endometrial epithelial cells remodelling. Scientific Reports 9: 12968. https://doi.org/10.1038/s41598-019-49502-5 